\title{
Double-edged sword behaviour of gallic acid and its interaction with peroxidases in human microvascular endothelial cell culture (HMEC-1). Antioxidant and pro-oxidant effects ${ }^{\star}$
}

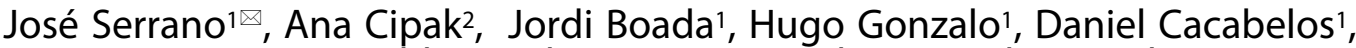 \\ Anna Cassanye1, Reinald Pamplona1', Neven Zarkovic² and Manuel Portero-Otin 1 \\ ${ }^{1}$ NUTREN Department of Experimental Medicine, University of Lleida-IRBLleida, Lleida, Spain; bDivision of Molecular Medicine, Rudjer Boskovic \\ Institute, Zagreb, Croatia
}

\begin{abstract}
A previous report from our group had shown in vitro a direct interaction between peroxidases and dietary antioxidants at physiological concentrations, where in the absence of $\mathrm{H}_{2} \mathrm{O}_{2}$, the antioxidants could serve as oxidizing substrates for the peroxidases. However, the physiological relevance of those findings had not been evaluated. The main objective of this study was to determine whether the oxidizing products produced in the interaction between peroxidase and gallic acid at a physiological concentration of $1 \mu \mathrm{M}$ may promote cell death or survival in a human microvascular endothelial cell line (HMEC-1). Our findings suggested that gallic acid may show a double-edged sword behaviour, since in the absence of $\mathrm{H}_{2} \mathrm{O}_{2}$ it may have a pro-oxidant effect which may promote cell injury (evidenced by LDH, Crystal Violet and calcein $A M$ viability/citotoxicity assays), while in the presence of $\mathrm{H}_{2} \mathrm{O}_{2}$, gallic acid may act as an antioxidant inhibiting oxidative species produced in the peroxidase cycle of peroxidases. These observations were confirmed with several oxidative stress biomarkers and the evaluation of the activation of cell survival pathways like AKT and MAPK/ERK.
\end{abstract}

Keywords: gallic acid, antioxidant, pro-oxidant, peroxidase, HMEC-1 Received: 11 December, 2009; revised: 06 May, 2010; accepted: 03 June, 2010; available on-line: 8 June, 2010

\section{INTRODUCTION}

There is now increasing experimental and clinical evidence showing involvement of oxidative stress in the pathogenesis of atherosclerosis (Harrison et al., 2003; Yokoyama, 2004). It is well known that during endothelial inflammation with activated macrophages several reactive intermediates (e.g., hypochlorus acid, chloramines, tyrosyl radicals and nitrogen dioxide) produced by the interaction between myeloperoxidase (MPO) and hydrogen peroxide may promote the oxidation of lipoproteins (Heinecke, 2003). Inmunohistochemical assays have shown the presence of MPO in human atherosclerotic lesions, thus implicating them in in vivo LDL modification and atherogenesis (Daugherty et al., 1994). At least three mechanisms involved in MPO-induced vascular injury responses have been described: consumption of nitric oxide, oxidation of LDL, and reaction with Larginine and protein to produce endogenous nitric oxide synthase inhibitors (Lee et al., 2009; Royet al., 2009; Schindhelm et al., 2009). All these mechanisms are hy- drogen peroxide-dependent. Therefore, several studies have been undertaken to understand the mechanism of this process and to propose actions that may inhibit the oxidative compounds produced within this system.

In this context, polyphenol intake has been related with the prevention of atherome plaque formation, since they may act as antioxidants and anti-inflammatory agents in vivo (Grassi et al., 2009; Hu, 2009). However, their molecular actions in cardiovascular disease prevention are not fully understood yet. It is suggested that flavonoids may act as co-substrates of MPO in the presence of $\mathrm{H}_{2} \mathrm{O}_{2}$, resulting in the formation of oxidized flavonoids possibly by two sequential one-electron reduction steps, generating compound II and the ferric form of MPO (Shiba et al., 2008). However, the role of those oxidized flavonoids in human pathology is still a focus of discussion. In addition, a strong inhibitory effect of quercetin aglycone on the MPO-catalyzed oxidation reaction has been demonstrated in vitro (Pincemail et al., 1988; Kato et al., 2003), which may reduce the formation of oxidizing compounds. It has also been demonstrated that gallates may strongly inhibit the enzyme activity, albeit out concentrations higher (around $30 \mu \mathrm{M}$ to $40 \mu \mathrm{M}$ ) than physiological ones (Kato et al., 2003; Rosso et al., 2006). On this basis it is plausible that the inhibition of MPO activity by polyphenols might be one mechanism for the prevention of cardiovascular disease.

Nevertheless, even if increasing evidence supports the role of oxidation in atherogenesis, the protective effect of dietary antioxidants in the human is still debated and controversial. The LDL resistance to oxidation does not systematically correlate with its antioxidant content; the degree of lipid peroxidation in atherosclerotic tissue also fails to correlate with the extent of lesion formation, while considerable amounts of antioxidants can be observed in atherosclerotic lesions (Witting et al., 1999).

In this context the in vitro results from our group may explain a double-edged sword behaviour of dietary antioxidants in their interaction with peroxidases, where in the absence of hydrogen peroxide or organic hydroperoxides the peroxidases may use dietary antioxidants as

\footnotetext{
\e-mail: jceserrano@mex.udl.cat

* Presented at the COST B-35 Work Group 4 Open Workshop "Natural and synthetic antioxidants", September 25-26, 2009, Rzeszów, Poland.

Abbreviations: $\mathrm{CML}_{1} \mathrm{~N}$-carboxymethyl lysine; DNP, dinitrophenyl; HMEC-1, human endothelial cell culture; HRP, horseradish peroxidase; LDH, lactate dehydrogenase; LDL, low-density lipoprotein; MDA-lys, malondialdehyde-lysine; MPO, myeloperoxidase; PBS, phosphate-buffered saline.
} 
oxidizing substrates to induce oxidation of other organic molecules (Serrano et al., 2009). However, the physiological relevance of these findings is unknown.

On the basis of this information, the main objective of this study was to determine the physiological implications of the oxidizing products generated in the interaction between peroxidases and gallic acid, at a physiological concentration of $1 \mu \mathrm{M}$, in the absence of hydrogen peroxide in a human microvascular endothelial cell line (HMEC-1). Crystal Violet toxicology assay, Calcein AM viability/cytotoxicity assay and lactate dehydrogenase activity were evaluated to determine cell survival under these conditions as well as the activation of AKT and MAPK/ERK cell survival pathways. Furthermore, oxidative stress biomarkers like carbonyl adducts, neuroketals, MDA-lysine adducts and carboxymethyl lysine adducts were determined under this conditions.

\section{MATERIALS AND METHODS}

Materials. Gallic acid monohydrate (328225) and Crystal Violet (C0775) were purchased from SigmaAldrich. Lactate dehydrogenase (LDH) was measured with the CytoTox $96^{\circledR}$ non-radioactive cytotoxicity assay from Promega (Madison, WI, USA). Calcein AM (C3099) was purchased from Molecular Probes. Horseradish peroxidase (HRP) (A-12216) was purchased from Molecular Probes. Primary antibodies for Western blotting are described in Table 1. For cell culture, human microvascular endothelial cell line (HMEC-1) was kindly provided by Dr. Anne Négre-Salvayre (INSERM, Toulouse, France). DMEM (BE12-614F) was purchased from BioWhittaker. MEM (51200), FBS (10270-106), penicillin and streptomycin (15140) and L-glutamine (25030) were purchased from Gibco.

Cell culture. HMEC-1 is an immortalized human microvascular endothelial cell line that retains the morphologic, phenotypic, and functional characteristics of normal human microvascular endothelial cells (Ades et al., 1992). HMEC-1 cells were grown in DMEM supplemented with $10 \%$ fetal bovine serum, $2 \mathrm{mM}$ L-glutamine and penicillin/streptomycin $(1000 \mathrm{U} / \mathrm{mL}$ and $1000 \mu \mathrm{g} / \mathrm{L}$ respectively). Cells were maintained at $37^{\circ} \mathrm{C}$ in a humidified atmosphere of $5 \% \mathrm{CO}_{2}$. In all experiments cells were grown until confluence and then transferred to 6or 96-well plates.

Calcein AM viability assay. Calcein AM viability assay is based on the principle that live cells are distinguished by the presence of ubiquitous intracellular esterase activity, determined by the enzymatic conversion of nonfluorescent cell-permeant calcein AM to the intensely fluorescent calcein (excitation/emission 495 $\mathrm{nm} / 515 \mathrm{~nm}$ ) (Papadopoulus et al., 1994). For the viability assay HMEC-1 cells were grown until confluence in DMEM 10\% fetal bovine serum and transferred to a 96-well plate and maintained for $24 \mathrm{~h}$ in MEM supplemented with $0.5 \%$ fetal bovine serum. Twelve wells were used per experimental treatment which included: control, gallic acid $1 \mu \mathrm{M}, \operatorname{HRP}(2 \mathrm{U} / \mathrm{mL})+$ gallic acid $1 \mu \mathrm{M}$ and each of these three groups with $\mathrm{H}_{2} \mathrm{O}_{2}(200$ $\mu \mathrm{M})$. All compounds were suspended in MEM without phenol red and without fetal bovine serum. After $24 \mathrm{~h}$ of incubation in their corresponding experimental treatment, $100 \mu \mathrm{L}$ of working solution containing $2 \mu \mathrm{M}$ calcein $\mathrm{AM}$ was added to each well and then incubated at room temperature for $45 \mathrm{~min}$. Fluorescence (excitation/ emission 495/515) was measured for the determination of live cells. Cell viability was determined by comparing the values of calcein fluorescence with those for control cells.

Crystal Violet assay. HMEC-1 cells were cultured and treated following the same procedure employed in the calcein AM viability assay described above. After $24 \mathrm{~h}$ of incubation with the corresponding experimental treatment, the medium was removed and cells were washed with $200 \mu \mathrm{L}$ of PBS and then incubated for 20 min with Crystal Violet $(0.2 \%)$. After incubation, plates were rinsed with tap water and $100 \mu \mathrm{L}$ of sodium dodecyl sulphate $(1 \%)$ was added and the absorbance of each well was measured using a microplate reader at $570 \mathrm{~nm}$. Cell viability was determined by comparing the absorbance reading relative to control treatment.

LDH-based toxicity assay. HMEC-1 cells were cultured and treated following the same procedure employed in the calcein AM viability assay described above. After $24 \mathrm{~h}$ of incubation with the corresponding experimental treatment, $10 \mu \mathrm{L}$ of lysis solution was added to 6 of 12 wells in each group, and $10 \mu \mathrm{L}$ of Hanks balanced solution to the other 6 wells in each group. The wells where Hanks balanced solution was added served to measure the amount of $\mathrm{LDH}$ released in the medium, and the wells where the lysis solution was added served to measure the total LDH content (culture-released and intracellular). After $30 \mathrm{~min}$ of incubation $50 \mu \mathrm{L}$ of the supernatant was transferred to an enzymatic assay plate, $50 \mu \mathrm{L}$ of $\mathrm{LDH}$ substrate mix was added and incubated for $30 \mathrm{~min}$ at room temp., protected from light. Later 50 $\mu \mathrm{L}$ of stop solution (1 $\mathrm{M}$ acetic acid) was added to each well and the absorbance was recorded at $490 \mathrm{~nm}$. Cell viability was measured by relating the content of $\mathrm{LDH}$ in the supernatant and to that after lysis.

Analysis of oxidative stress markers and cell survival pathways. Oxidative lesions were evaluated by western blot using anti-DNP (carbonyl adducts formation), N-epsilon-(carboxymethyl) lysine (CML), neuroketal-adducted proteins and malondialdehyde-lysine (MDAlys) adducts. The activation of AKT and MAPK/ERK were used to measure the activation of cell survival pathways. Proteasomal stress was measured by the activa-

Table 1. Primary and secondary antibodies used for Western blot immunodetection

\begin{tabular}{lll}
\hline Antigen & Supplier & Dilution \\
\hline DNP & Sigma & $1: 2000$ \\
CML & Transgenic & $1: 1000$ \\
Neuroketals & Abcam & $1: 500$ \\
MDA-lys & Biomedical company & $1: 300$ \\
AKT & Biosource & $1: 1000$ \\
p-AKT & Cell signaling & $1: 1000$ \\
MAPK/ERK & Cell signaling & $1: 1000$ \\
p-MAPK/ERK & Cell signaling & $1: 1000$ \\
Ubiquitin & Sigma & $1: 100$ \\
elF2a & Abcam & $1: 1000$ \\
p-elF2a & Cell signaling & $1: 1000$ \\
$\beta$-Actin & Sigma & $1: 3000$ \\
Anti-mouse IgG & Amersham & $1: 30000$ \\
Anti-rabbit lgG & Pierce & $1: 100000$ \\
Anti-goat IgG & Vector & $1: 15000$ \\
\hline
\end{tabular}


tion of eIF $2 \alpha$ and the degree of protein ubiquitination. HMEC-1 cells were incubated as described above for cell viability determination in 6-well plates. After treatments, cells were lysed using RIPA buffer with protease and phosphatase inhibitors. Protein concentrations were measured using the Lowry assay (BioRad Laboratories, München, Germany) with bovine serum albumin as a standard. Total protein $(15-40 \mu \mathrm{g})$ was resolved by SDSPAGE and electroblotted onto polyvinylidene difluoride membranes (Immobilon-P Millipore, Bedford, MA, USA). Immunodetection was performed using as primary and secondary antibodies those listed in Table 1. A monoclonal antibody to $\beta$-actin (Sigma, USA) was used to control protein loading. Protein bands were visualised with the chemiluminescence ECL method (Millipore Corporation, Billerica, MA, USA). Luminescence was recorded and quantified in a Lumi-Imager equipment (Boehringer, Mannheim, Germany), using the Quantity One 4.6.5. software.

Statistical analysis. All statistics were performed using the SPSS software (SPSS Inc., Chicago, IL, USA). Differences between groups were analyzed by one way Anova. The 0.05 level was selected as the point of minimal statistical significance in every comparison.

\section{RESULTS}

\section{In vitro toxicity assays}

Three in vitro toxicity assays were employed to asses the effects of oxidative agents produced by the interaction of peroxidase and gallic acid as shown in Fig. 1. The experimental model included the incubation of HMEC-1 cells for $24 \mathrm{~h}$ with gallic acid $(1 \mu \mathrm{M})$ and its combination with HRP peroxidase in the presence or absence of $\mathrm{H}_{2} \mathrm{O}_{2}$. The three viability/toxicity assays employed showed almost the same results. In all cases, gallic acid seem to induce cell survival/proliferation, while HRP did not induce any effect on cell survival/proliferation as observed by the calcein AM and LDH toxicity assay. It is also evidenced that the protecting effect of gallic acid in HMEC-1 cells could be counteracted by the incorporation of HRP peroxidase in the system.

As negative controls cells were cultured with high amounts of $\mathrm{H}_{2} \mathrm{O}_{2}(200 \mu \mathrm{M})$ to induce cell injury. In the three viability/toxicology assays tested the cell viability was reduced considerably by the addition of $\mathrm{H}_{2} \mathrm{O}_{2}$ to the medium (Fig. 1). The addition of HRP or gallic acid inhibited the cell injury induced by $\mathrm{H}_{2} \mathrm{O}_{2}$, however, their beneficial effects were lost when both HRP and gallic acid were added.

\section{MAPK/ERK and AKT pathway analysis}

Cell survival pathways were assessed to confirm the results obtained by the toxicity assays. The MAPK/ ERK pathway is a signal transduction pathway that couples intracellular responses to the binding of growth factors to cell surface receptors. In the same manner, AKT is involved in cellular survival pathways, by inhibiting apoptotic processes. Results from the analysis of these pathways are shown in Fig. 2. As controls for the inhibition of these pathways, the incubation of the cell line under high concentration of $\mathrm{H}_{2} \mathrm{O}_{2}(200 \mu \mathrm{M})$ which is assumed to induce cell death was employed. The activity of both pathways was re-
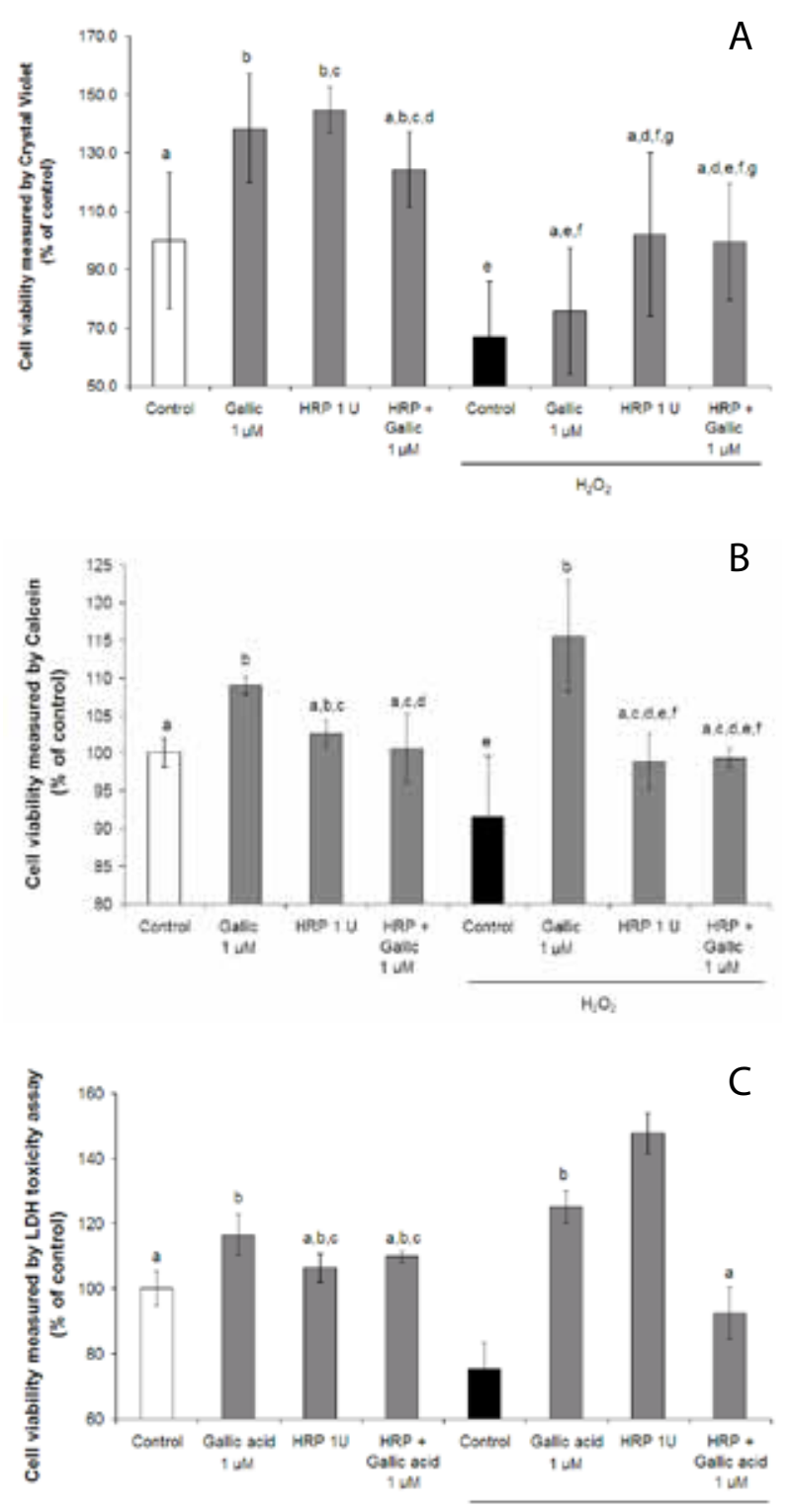

Figure 1. Effects of HRP, gallic acid and $\mathrm{H}_{2} \mathrm{O}_{2}$ on viability of HMEC-1 cell culture.

Cell viability was measured by (A) Crystal Violet assay, (B) calcein AM cytotoxicity assay, and (C) LDH release to cell culture medium. Same letters between columns shows no statistically significant differences between groups $(P>0.05)$.

duced considerably under the treatment with $\mathrm{H}_{2} \mathrm{O}_{2}$. Under the experimental conditions studied, the treatment with gallic acid and HRP combined in the absence of $\mathrm{H}_{2} \mathrm{O}_{2}$ reduced considerably the activation of both cell survival pathways, which resembles the results obtained in cell toxicology assays. The inhibition of the MAPK/ERK pathway by gallic acid + HRP peroxidase was similar to the inhibition observed in the control group exposed to high concentration of $\mathrm{H}_{2} \mathrm{O}_{2}(200 \mu \mathrm{M})$ and with a major extent reduction in the AKT pathway signalling.

\section{Oxidative stress biomarkers}

Oxidative stress is also known to induce apoptosis in a variety of cell types by activating intracellular cell death signalling cascades (Martindale \& Holbrook, 2002). The purpose of assessing oxidative stress was 

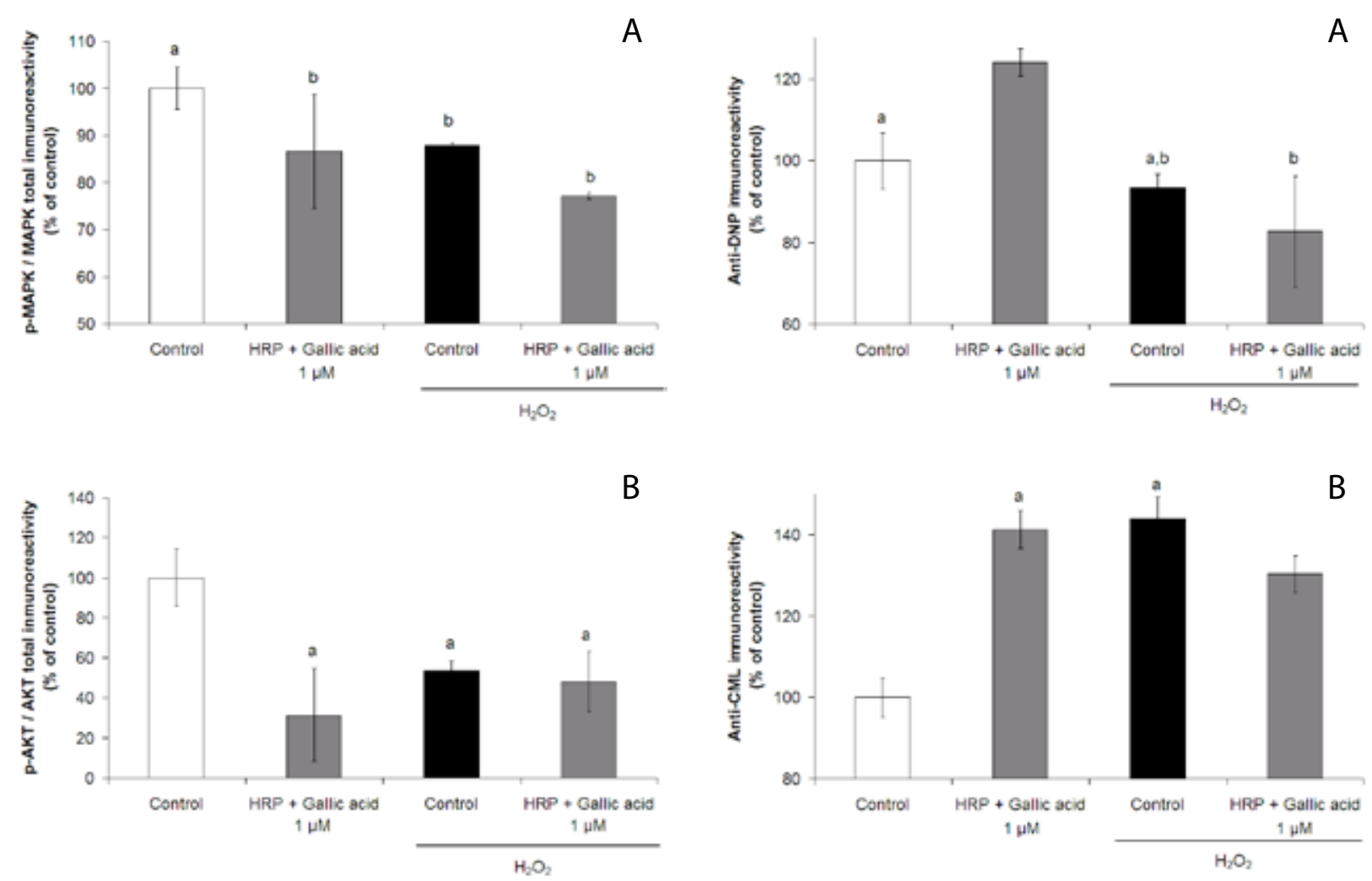

Figure 2. Effects of HRP, gallic acid and $\mathrm{H}_{2} \mathrm{O}_{2}$ on cell survival pathways.

MAPK/ERK (A) and AKT (B) pathways were analysed. Activation of these pathways is expressed as an increase in the amount of phospho-MAPK/ERK and phospho-AKT in relation to the total amount of MAPK/ERK and AKT, respectively. Same letters between columns shows no statistically significant differences between groups $(P>0.05)$.

to determine if the observed effects in the loss of cell survival could be attributed to the oxidative damage produced by the interaction between HRP and gallic acid. Four oxidative stress biomarkers were assessed as shown in Fig. 3. The results obtained were similar to those of the toxicity assays and cell survival pathways in the case of three (CML, MDA-lys and neuroketals) of the four stress biomarkers assessed. The experimental conditions (gallic acid + HRP, gallic acid $+\mathrm{HRP}+\mathrm{H}_{2} \mathrm{O}_{2}$, and control $+\mathrm{H}_{2} \mathrm{O}_{2}$ ) that caused a high oxidative stress showed also a high cell death rate and a poor activation of cell survival pathways. Anti-DNP immunoreactivity showed different results in relation to CML, MDA-lys and neuroketals oxidative stress biomarkers principally because it was observed a different oxidized protein pattern between treatments (Fig. 4) where an increase in specifics proteins oxidation was detected. Anti-ubiquitin and eIF2 $\alpha$ immunoreactivy was also evaluated to determine the rate of protein turnover, principally to determine whether or not the degree of oxidated protein could be due to accumulation of damaged proteins because of a lower proteosomal activity (Fig. 5). The grade of protein ubiquitination was higher when $\mathrm{H}_{2} \mathrm{O}_{2}$ was present as well as when gallic acid was added in combination with HRP. Increased eIF $2 \alpha$ phosphorylation, also observed under the latter condition, indicates high endoplasmatic reticulum stress which may lead to an impairment of the ubiquitin-proteosomal activity.
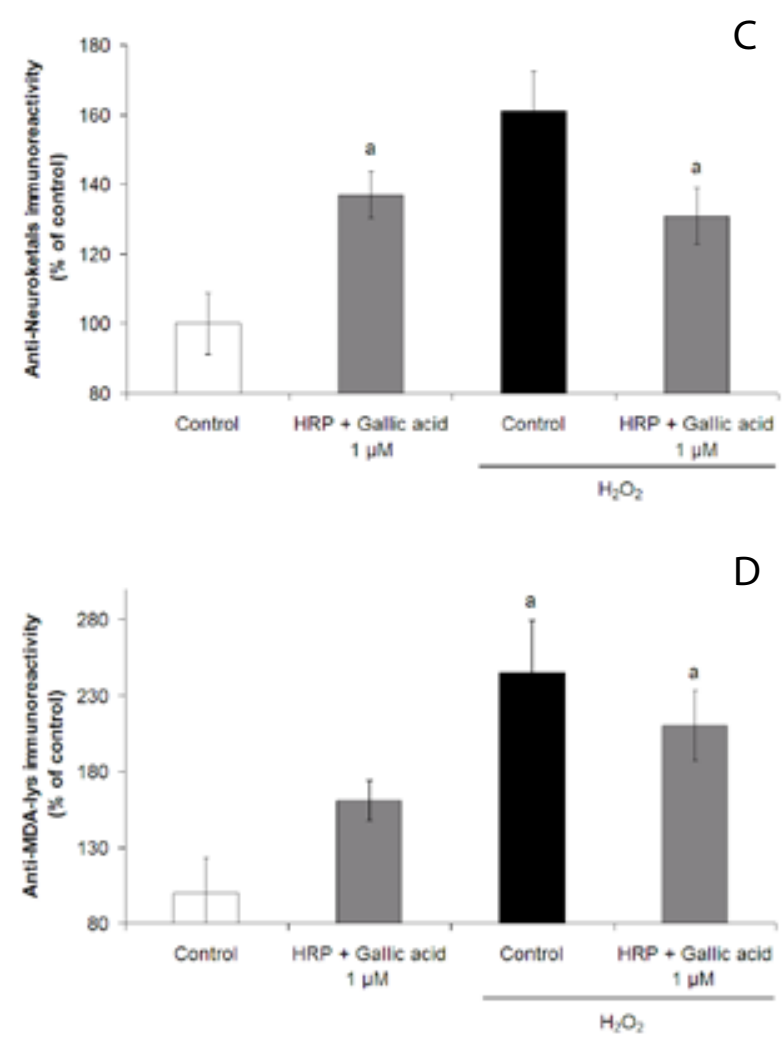

Figure 3. Oxidative damage induced by HRP, gallic acid and $\mathrm{H}_{2} \mathrm{O}_{2}$ in $\mathrm{HMEC}-1$ cell culture.

(A) Carbonyl adducts measured by dinitrophenyl derivatization, (B) $\mathrm{N}$-carboxymethyl lysine (CML), (C) neuroketal-adducted proteins and (D) malondialdehyde-lysine adducts. Same letters between columns shows no statistically significant differences between groups $(P>0.05)$. 


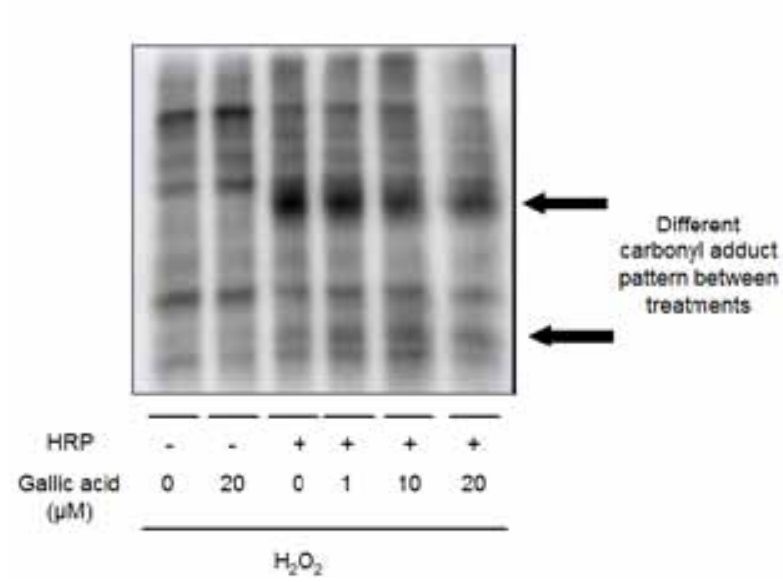

Figure 4. Western blot analysis of anti-DNP immunoreactivity after HRP, gallic acid and $\mathrm{H}_{2} \mathrm{O}_{2}$ treatment of HMEC-1 cell culture. Different protein oxidation patterns can be seen between groups.

\section{DISCUSSION}

The main purpose of this study was to elucidate the cellular responses induced by oxidative compounds produced by peroxidase + antioxidant in the absence of $\mathrm{H}_{2} \mathrm{O}_{2}$, conditions studied before in vitro (Serrano et al., 2009). At the cellular level, the oxidant injury produced in this system may elicit a wide spectrum of responses ranging from proliferation to growth arrest, senescence, and cell death (Martindale \& Holbrook, 2002; Cully \& Downward, 2009). In the case of endothelial cells, it is well known that excessive activation of the immune system during inflammation may cause host cell/tissue damage via harmful peroxidase activity and oxidizing compound production (Harrison et al., 2003; Yokoyama, 2004). This experiment was performed to mimic the effects to endothelial cells of peroxidase activity in the presence of antioxidant compounds without an inflammatory response.

The doses of peroxidase and gallic acid used were physiological (Manach et al., 2005; Mocatta et al., 2007). Almost no literature data was found regarding the physiological meaning of this interaction. Some authors have suggested that polyphenols may inhibit the enzymatic activity of peroxidases (Kato et al., 2003; Rosso et al., 2006; Shiba et al., 2008), therefore reducing the oxidative stress induced by peroxidase by-products. The doses of polyphenols employed in those studies were around 40 $\mu \mathrm{M}$, considerably higher than the physiological concentration of polyphenols and gallic acid in plasma $(0.2 \mu \mathrm{M}$ to $2 \mu \mathrm{M}$ ) (Manach et al., 2005). Moreover, those studies were performed on the basis of $\mathrm{HOCl}$ or tyrosyl radical formation without taking into consideration other oxidation by-products. In addition, previous experiments performed by our group suggest that above $10 \mu \mathrm{M}$, gallic acid may be toxic to HMEC-1 cell culture reducing considerably its viability.

Our results suggest that gallic acid with peroxidases shows dual behaviour in relation to the presence or absence of $\mathrm{H}_{2} \mathrm{O}_{2}$ in the medium: while in the presence of $\mathrm{H}_{2} \mathrm{O}_{2}$ it may act as an antioxidant inhibiting the generation of oxidizing products by $\mathrm{HRP}-\mathrm{H}_{2} \mathrm{O}_{2}$, in the absence of $\mathrm{H}_{2} \mathrm{O}_{2}$ it may act as oxidizing compound.

At the cellular level, the oxidative stress produced via the peroxidasen-gallic acid system (without $\mathrm{H}_{2} \mathrm{O}_{2}$ ) was
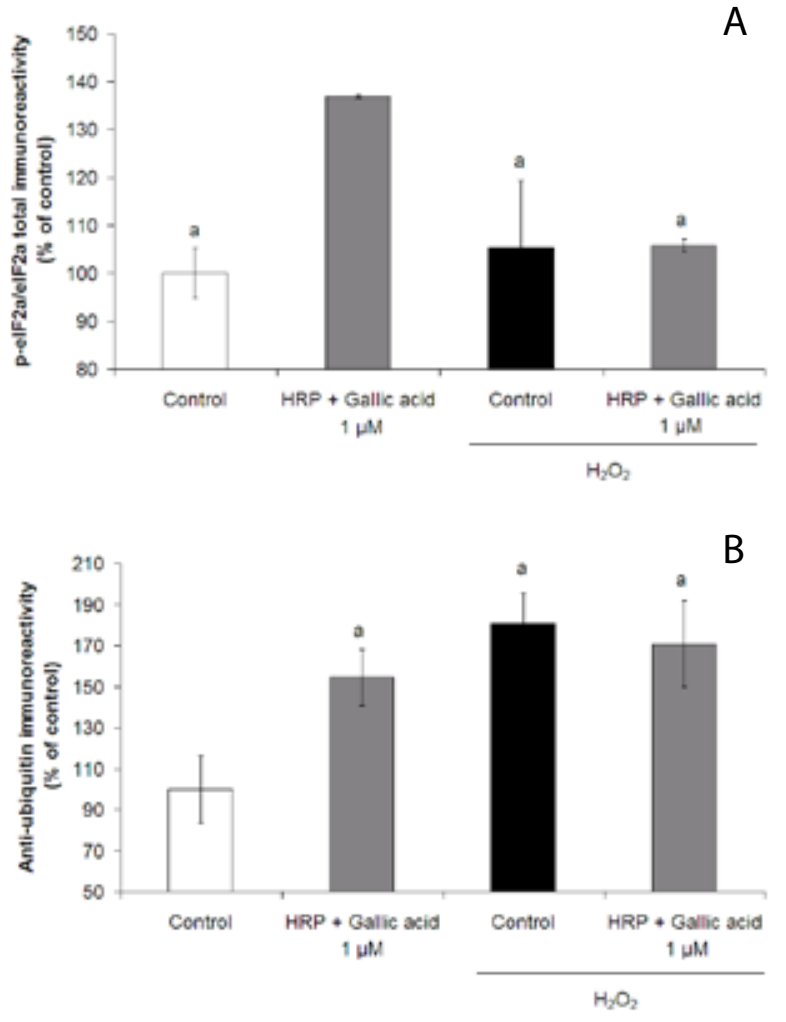

Figure 5. Effects of HRP, gallic acid and $\mathrm{H}_{2} \mathrm{O}_{2}$ on endoplasmatic reticulum stress.

The stress was measured by elF2a activation and the amount of ubiquitinated proteins. (A) elF2a activation was expressed as the increase in the amount of phosho-elF2 $\alpha$ in relation to the total amount of elF2a. (B) Ubiquitin content in relation to $\beta$-actin. Same letters between columns shows no statistically significant differences between groups $(P>0.05)$.

strong enough to produce oxidant injury to HMEC-1 cells, and may be responsible for the cell toxicity observed in the toxicity assays employed. The oxidative compounds produced in this system are unknown at the moment. However, as shown in Fig. 4, the oxidative compounds produced by peroxidase may have specific protein targets. The oxidative stress induced by the peroxidasen-gallic acid interaction (without $\mathrm{H}_{2} \mathrm{O}_{2}$ ) was also sufficient to inhibit MAPK/ERK and AKT cell survival signals, which may be a consequence of high oxidative stress, as evidenced by the oxidation biomarkers (MDA-lys, CML and neuroketals) analyzed and the high amount of ubiquitinated proteins. In the same context the high levels of ubiquitinated proteins observed could also be due to a low proteosomal activity caused by a high endoplasmatic reticulum stress (evidenced by high activation of $\mathrm{eIF} 2 \alpha$ ), reducing the folding capacity of the endoplasmatic reticulum, which results in the accumulation and aggregation of unfolded proteins.

It could be suggested that the oxidative compounds produced by the peroxidasen-gallic acid interaction (without $\mathrm{H}_{2} \mathrm{O}_{2}$ ) suffice to induce oxidation damage in HMEC-1 cell culture affecting cell functioning.

\section{Acknowledgements}

We thank M. Martin and D. Argiles for their skillful technical assistance. 
This study was supported by grants from the Spanish Ministry of Science and Innovation (CENIT METDEV-FUN) to M. Portero-Otín, the Spanish Instituto de Salud Carlos III (FIS PI081238) to J. Boada and (FIS PI081843) to M. Portero-Otin and by the COST action B35.

\section{REFERENCES}

Ades EW, Candal FJ, Swerlick RA, George VG, Summers S, Bosse DC, Lawley TJ (1992) HMEC-1: establishment of an immortalized human microvascular endothelial cell line. I Invest Dermatol 99: 683-690.

Cully M, Downward J (2009) Translational responses to growth factors and stress. Biochem Soc Trans 37: 284-288.

Daugherty A, Dunn JL, Rateri DL, Heinecke JW (1994) Myeloperoxidase, a catalyst for lipoprotein oxidation, is expressed in human atherosclerotic lesions. J Clin Invest 94: 437-444.

Grassi D, Desideri G, Croce G, Tiberti S, Aggio A, Ferri C (2009) Flavonoids, vascular function and cardiovascular protection. Curr Pharm Des 15: 1072-1084.

Harrison D, Griendling KK, Landmesser U, Hornig B, Drexler H (2003) Role of oxidative stress in atherosclerosis. Am J Cardiol 91: 7A-11A.

Heinecke JW (2003) Oxidative stress: new approaches to diagnosis and prognosis in atherosclerosis. Am J Cardiol 91: 12A-16A.

$\mathrm{Hu}$ FB (2009) Diet and lifestyle influences on risk of coronary heart disease. Curr Atheroscler Rep 11: 257-263.

Kato Y, Nagao A, Terao J, Osawa T (2003) Inhibition of myeloperoxidase-catalyzed tyrosylation by phenolic antioxidants in vitro. Bioscience, Biotechnol Biochem 67: 1136-1139.

Lee JR, Kim JK, Lee SJ, Kim KP (2009) Role of protein tyrosine nitration in neurodegenerative diseases and atherosclerosis. Arch Pharm Res 32: 1109-1118.

Manach C, Williamson G, Morand C, Scalbert A, Rémésy C (2005) Bioavailability and bioefficacy of polyphenols in humans. I. Review of 97 bioavailability studies. Am J Clin Nutr 81: 230S-242S.
Martindale JL, Holbrook NJ (2002) Cellular response to oxidative stress: Signaling for suicide and survival. J Cell Physiol 192: 1-15.

Mocatta TJ, Pilbrow AP, Cameron VA, Senthilmohan R, Frampton CM, Richards AM, Winterbourn CC (2007) Plasma concentrations of myeloperoxidase predict mortality after myocardial infarction. $J$ Am Coll Cardiol 49: 1993-2000.

Papadopoulus NG, Dedoussis GVZ, Spanakos, Gritzapis AD, Bazevanis CN, Papamichail M (1994) An improved fluorescence assay for the determination of lymphocyte cytotoxicity using flow cytometry. J Immunol Methods 177: 101-111.

Pincemail J, Deby C, Thirion A, de Bruyn-Dister M, Goutier R (1988) Human myeloperoxidase activity is inhibited in vitro by quercetin. Comparison with three related compounds. Experientia 44: 450-453.

Rosso R, Vieira TO, Leal PC, Nunes RJ, Yunes RA, Creczynski-Pasa TB (2006) Relationship between the lipophilicity of gallic acid $n$-alquil esters' derivatives and both myeloperoxidase activity and $\mathrm{HOCl}$ scavenging. Bioorg Med Chem 14: 6409-6413.

Roy H, Bhardwaj S, Yla-Herttuala S (2009) Molecular genetics of atherosclerosis. Hum Genet 125: 467-491.

Schindhelm RK, Van Der Zwan LP, Teerlink T, Scheffer PG (2009) Myeloperoxidase: A useful biomarker for cardiovascular disease risk stratification? Clin Chem 55: 1462-1470.

Serrano J, Jové M, Boada J, Bellmunt MJ, Pamplona R, Portero-Otín M (2009) Dietary antioxidants interfere with Amplex Red-coupledfluorescence assays. Biochem Biophys Res Commun 388: 443-449.

Shiba Y, Kinoshita T, Chuman H, Taketani Y, Eiji Takeda, Kato Y, Naito M, Kawabata K, Ishisaka A, Terao A, Kawai Y (2008) Flavonoids as substrates and inhibitors of myeloperoxidase: molecular actions of aglycone and metabolites. Chem Res Toxicol 21: 1600-1609.

Witting P, Pettersson K, Östlund-Lindqvist A, Westerlund C, Wågberg M, Stocker R (1999) Dissociation of atherogenesis from aortic accumulation of lipid hydro(pero)xides in Watanabe heritable hyperlipidemic rabbits. J Clin Invest 104: 213-220.

Yokoyama M (2004) Oxidant stress and atherosclerosis. Curr Opin Pharmacol 4: 110-115. 